IJMS 26 (1), 73-97 (2019)

How to cite this article:

Kim, J., \& Zhao, X. (2019). A study of strategic group based on main melody analysis - application on an industry in China. International Journal of Management Studies, 26(1), 73-97.

\title{
A STUDY OF STRATEGIC GROUP BASED ON MAIN MELODY ANALYSIS - APPLICATION ON AN INDUSTRY IN CHINA
}

\author{
JONGHO KIM \\ XINAN ZHAO* \\ School of Business Administration \\ Northeastern University, Shenyang, China \\ *Corresponding Author: xnzhao@mail.neu.edu.cn
}

\begin{abstract}
At present, the tremendous change in the industrial environment affects both enterprise and industry, while the core values of strategic management are also being transformed into innovation, collaboration and common development in line with the idea of sustainable development. In this paper, a method of studying strategic group was proposed on the basis of current thinking about the relationship between enterprises in industry and corporate strategic behavior and subsequently its application was illustrated in the performance data of 41 listed companies in an industry in China in 2012-2016. The main melody analysis based on synergy and Jingyou theory was used to classify and analyze the strategic groups in industry. Results obtained from this study such as the distributive features of strategic groups in industry, the main developing mode of industry, the main strategic group, the benchmark and synergistic partner will be of significance in the development of strategic group theory and the practice of modern strategic management.
\end{abstract}

Keywords: Jingyou, main melody analysis, organizational values, strategic group, synergy.

Received: 21/5/2019 Revised: 25/10/2019 Accepted:30/12/2019 Published: 31/1/2020 


\section{Introduction}

Today, extensive changes have taken place in all aspects of human, social and economic life as well as the industrial environment. The symbiosis, relevance and interactivity between enterprises in an industry or different industries have gradually formed a new dynamic developing system, while the establishment of an industrial ecosystem has been regarded as an important practice for sustainable development. Everyone has recognized that if an enterprise is to be developed, it should build up a collaborative economic group with other enterprises. The appearance of "commercial ecosystem" suggested by Moore (1996) made it possible to break the limitations of traditional strategic management theory based on competition and to seek "co-evolution". As competition is likely to lose its universal significance, the core values of strategic management are being evolved from self-centred development based on competition to codevelopment based on innovation and collaboration.

The study of strategic group is very important in modern strategic management practice, in which the enterprise can not only grasp the strategic structure and economic situation in industry but also explore strategic pathways for its future development. Firstly, the enterprise needs to accurately identify which group it belongs to. According to the identification result, the enterprise can either seek opportunities for its growth or face unexpected obstacles and threats, which in turn depend on its organizational values and strategic consciousness of corporate behavior. In other words, the strategic feature of corporate behavior is determined by its organizational values and strategic consciousness. Secondly, scientific analysis should be carried out on the industrial structure, the relationship between enterprises and the economic situation in industry or strategic group on the basis of the objective law of the development of things.

With changes in the industrial environment and the value ideology of modern strategic management, it is necessary to study the strategic group focusing on the growth of enterprise and the development of industry using new strategic thinking rather than traditional theories. This is because most of these theories overemphasized competition or the competitive environment in the study of strategic groups. In fact, it is difficult to solve such problems faced by modern 
strategic management practices as the innovation in the value creation mechanism and the reorganization of industrial structures depend on competition; in particular, a vicious competition which causes not only the serious depletion of resources but the destruction of the industrial ecosystem. The purpose of this paper is to establish a strategic group analysis method and its application paradigm based on a new theoretical interpretation of the relationship between enterprises in strategic groups and corporate strategic behavior, the theoretical bases of which are synergistic and the Jingyou theory that have become current issues in modern management science.

\section{Literature Review}

Hunt (1972) initiated the concept of "strategic group". Porter (1980) defined the strategic group as a group of enterprises with the same strategies in an industry. McGee and Thomas (1986) pointed out that it represented an integration of enterprises similar to each other in terms of the allocation of resources and abilities. It had been used to classify strategic groups by using strategic variables such as vertical integration, diversification and differentiation of products, scale of enterprise, and types of strategies accepted by enterprises such as Porter's cost strategy (Hunt, 1972; Porter, 1979; Dess \& Davis, 1984). Vincent (1999) described a case study on the formation of a technological revolution and strategic group. It was carried out to study the relationships between enterprises, strategic groups and performance based on resource scarcity theory and economic perspective (Jose, Juan, \& Isabel, 2004). James and Hugh (2004) regarded the exit barrier between strategic groups as a control parameter of relationship between strategy and performance. Enrique, Jose and Jorge (2006) argued that the strategic group analysis was a useful tool in building competitive strategy. Diego and Jordi (2006) identified strategic groups in industry by using data envelopment analysis (DEA). Kuofeng (2009) described how strategic groups dealt with cognitive complexity to maintain their competitive advantage.

Some of the methods for identifying strategic groups has been proposed such as using factor analysis, genetic evolutionary computation, two-step clustering and regression analysis (MartinazTorres \& Toral-Marin, 2010), Aaron, Heather, Stephen \& JohnAaron, 
2011; B. P. S., Abdul, \& Irene, 2013). Raphael, Noureddine, and Thierry (2012) explained the relationships between enterprise, strategic group and performance from a cognitive perspective. It was conducted to study the use of strategic group map as a tool for competitive strategy analysis and knowledge management, the application of strategic group analysis in the choice of business strategies of multinational corporations, interaction between enterprises in strategic groups in pricing and sales, organizational cognitive mechanism in competition and cooperation, the relationship between strategic group affiliation and performance in the insurance industry, behavioral patterns of enterprises engaged in global engineering industries, formation mechanism of strategic groups via the introduction of game theory into agent-based models, and the relationship between implementation of lean manufacturing practices and the choice of performance objectives in an auto parts industry (Michal, Joanna, Krzysztof, \& Andrzej, 2015; Yiannis, Anastasios, \& Panos, 2017; Jeannet \& Schreuder, 2015; John, William, \& Michae, 2016; Scott, Kristen, \& Otilia, 2017; Muhammed, Jannes, \& Sabine, 2016; Y. R., J. P., \& K. T., 2016; Andrew \& Erika, 2017; Hamilton, Orlando, \& Takeshy, 2017). A spatial analysis method was suggested by using the improved McKinsey matrix (Hanna \& Agnieszka, 2017). Sofiane, Magali, Muriel, and Frederic (2017) classified the French franchising industry into five main strategic groups. It was performed to analyze the impact of rivalry between strategic groups on the performances of companies, the important role of strategic groups in the choice of entry mode into foreign markets and the similar strategic behaviors of public companies through application researches in various industries (Francisco \& Felipe, 2017; Francisco, Mas, Ruiz, \& Calderon, 2018; Carlos, Mariya, \& Sofia, 2018). It was noted that enterprises reacted more strongly to rivals in their own strategic groups than in industry (Leon, Stephan, \& Tobias, 2018). Andrew (2019) argued that the larger the strategic group, the more it added to the overcrowding issue, therefore, the size of strategic groups should be balanced with access to a strategy(s).

The above researches provided a technical support for the strategic reorganization of industrial structure, the building of competitive strategies, decision-making on investments, training of core abilities, etc. However, most of them were generally based on competitive mechanisms, that is, they still focused on competition or the 
capturing of competitive advantage in industry by using strategic group theory. For example, they believed that there exists only competitive relationships between enterprises in the same strategic group and the purpose of strategic group analysis is to identify the competitors and the mobile barriers in industry. Moreover, they have not paid attention yet to the structural feature of strategic groups, its formation and development mechanism, and corporate behavior from the standpoints of the objective law of development of things and the core values of modern strategic management.

\section{Theoretical Interpretation Synergy: The Relationship between Enterprises in Strategic Groups and Corporate Behavior}

According to Haken (1977), there will be order and disorder in various things of nature and human society, which may be converted to each other under certain conditions. The order is synergy, but the disorder is chaos. The so-called "synergy" refers to the interaction between two or more individuals and the differences they bring in to achieve their common goal or benefit. It results in positive effects on the growth of the individuals as well as the development of the group. Without this, the people cannot survive, production cannot be developed, and society cannot move forward. The synergy theory studies the common features of different things and the comprehensive synergistic effect between them, which focuses on the similarity of systems when they change from disorder to order.

Generally, all individuals have the following characteristics: 1) they have personal and group goals; 2) they possess personal and group consciousness; 3 ) there will be exchanges, competition and collaboration between them. Personal goal and consciousness based on the values of self-centred development are the preconditions of competitive behavior, while the group goal and consciousness based on the values of co-development result in synergistic behavior such as exchange and collaboration. That is, individual behavior can be classified as competitive or synergistic according to its values. The competitive behavior may be regarded as a driving force for the growth of the individual at any time. But the individual exists in a group, and its behavior is formed and evolved in a group environment. Needless to say, there is no growth of the individuals without the group, so the individual also pursues synergistic behavior. The group goal and 
consciousness are bases in the formation of a group, while synergistic behavior is a driving force for the co-development of individuals and groups, which is an objective law of development of things.

The strategic group is a group of enterprises formed by a social and economic relationship, and there will be competition as well as synergy between enterprises in a group. Meanwhile, corporate behavior can also be classified as competitive or synergistic according to its organizational values. The synergistic behavior contributes much more to the development of enterprises and strategic groups than competitive behavior because it realizes the effective collaboration of resources and abilities between enterprises in groups and further enables overcoming of mobile barriers between different strategic groups. Even if competitive behavior is necessarily needed for the growth of enterprises, it should comply with the synergistic behavior to achieve a common goal of the group. Figure 1 shows the relationship between organizational values, corporate strategic behavior and performance of strategic groups.

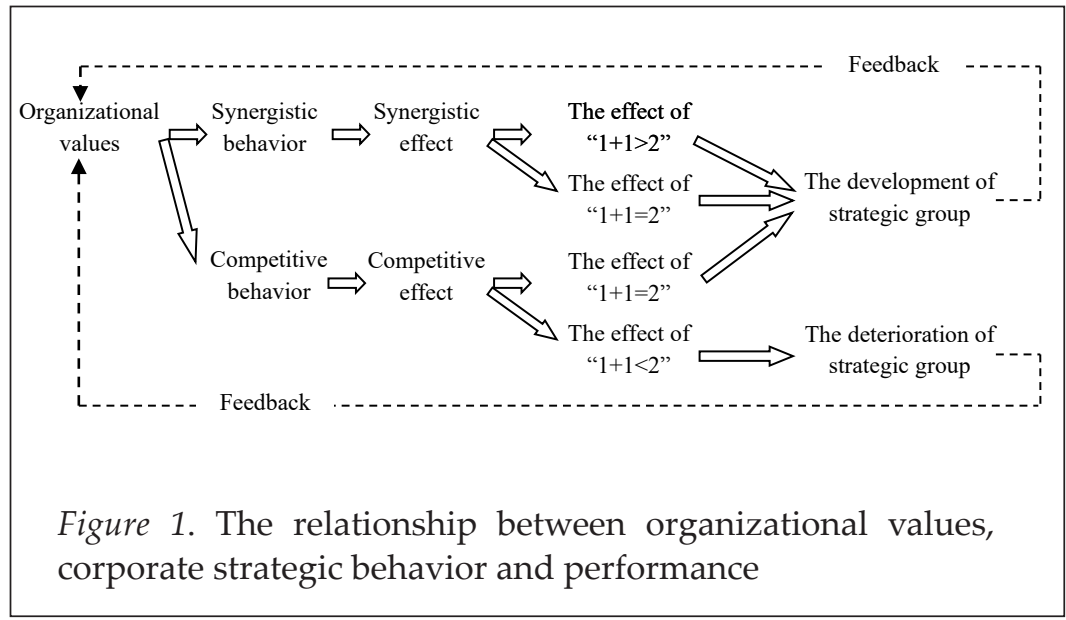

\section{Jingyou: Individual Advantage Characteristics and Main Melody Analysis}

Xinan, Bingdong, and Huimin (2006) put forward the Jingyou idea. They argued that people should strive to explore and use natural laws to unveil their own excellence in improving the environment 
and creating benefits for mankind rather than competing, which is named "Jingyou". They also explained that the master of behavior is an objective being with social attributes which exists in the organizational environment, the values and behavior of which directly affects its growth as well as the development of its organization; therefore, it should pursue the co-development of its organization and realize its own values through contributions to the organization. Jingyou is a behavior of the individual as a social being based on the synergistic mechanism in an organization which implies the strategic idea of sustainable development era. The Jingyou evaluation theory including the identification of individual advantage characteristics, the agent evaluation and the main melody analysis was proposed on the basis of Jingyou idea.

The individual advantage characteristic is a kind of essential structure that corresponds to the indicator system that can best reflect the value of individuals under organizational values, which will be formed through the growth of individuals based on the understanding of the objective law of things and the practice for the benefit of the organization. That is, it is a reflection of individual behavior based on organizational values. When a strategic group is formed, there should be a structure of individual advantage characteristics as a comprehensive reflection of all corporate strategic behaviors in it, which changes as the group evolves.

It is important to find a universal Jingyou behavioral mode for improving the management of social groups in a Jingyou environment, which is regarded as the main melody of the group. The main melody analysis is a method of analyzing the impact of themes implied in main melody on social groups, which is based on the identification of individual advantage characteristics. In other words, each melody in a social group corresponds to a value structure of individual advantage characteristics that represents individual behavior (Xinan, Chunhong, \& Yanmei, 2012). All enterprises have their own melodies, while the strategic groups have their common melodies, of which the main melody reflects the main developing mode of industry. Therefore, it is possible to not only understand the corporate strategic behavior but identify the groups with different strategic features in industry by using the analysis of melodies of enterprises in industry. 
IJMS 26 (1), 73-97 (2019)

\section{Methodology}

The method proposed in this paper is divided generally into two parts: the classification of strategic groups in industry and their industrial environment analysis. The framework of the method is shown in Figure 2.

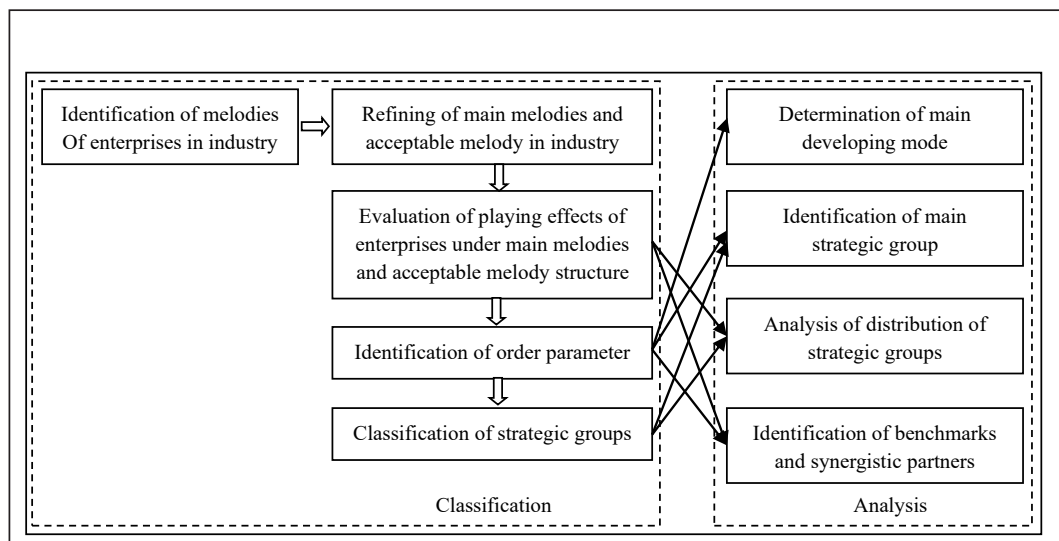

Figure 2. Framework of the method proposed in this paper

\section{Classification of Strategic Groups}

\section{Identification of Individual Advantage Characteristics-Melody of Enterprise in Industry}

An ideal point utility model is used to identify individual advantage characteristics, if $m$ is the number of indicators and $n$ is the number of enterprises in an industry, the equation of identification is as follows:

$$
\begin{gathered}
\min _{w} d^{2}\left(f_{i}, \tilde{f}\right)=\sum_{j=1}^{m} w_{i j}^{2}\left(f_{j}\left(x_{i}\right)-\tilde{f}_{j}\right)^{2}=\sum_{i j}^{m} w_{i j}^{2}\left(f_{i j}-\tilde{f}\right)^{2} \\
\text { s.t. } \sum_{j=1}^{m} w_{i j}=1 \\
w_{i j} \geq 0, j=1,2, \ldots, m, i=1,2, \ldots, n
\end{gathered}
$$

where $f_{i j}$ is an observed value for index $i$ of enterprise $x_{i}, f_{i}$ is an index value vector of $x_{i}, w_{i}=\left(w_{i 1}, w_{i 2}, \ldots, w_{i m}\right)^{\tau}$ is a value structure of individual advantage characteristics obtaied for $x_{i}$, 
$\tilde{f}=\left(\widetilde{f}_{1}, \widetilde{f}_{2}, \ldots, \widetilde{f}_{m \alpha}\right)$ is an ideal value vector, $d\left(f_{i}, \tilde{f}\right)$ is a distance between $f_{i}$ and $f$ under the value structure $w_{i}$. The value structure identified for an enterprise corresponds to its melody.

\section{Refining of Main Melodies and Acceptable Melody}

After obtaining an aggregation of melodies for all enterprises, the enterprises in industry may be integrated into groups with different melody structural features by using cluster analysis. The melody structures of enterprises are similar to each other in a group. Among the representative melodies obtained through the cluster analysis, the melodies composed of more than 20 percent of all members in industry and thus can be considered as the main melodies of the industry based on the Pareto principle (Xinan, Chunhong, \& Yanmei, 2012).

There must be an acceptable melody for all enterprises in industry, the value structure of which is obtained from the equation (2).

$$
w^{*}=\frac{1}{n} \sum_{i=1}^{n} w_{i},
$$

\section{Playing Effect Under Main Melody and Acceptable Melody}

By substituting the value structure of each main melody and the result of equation (2) into equation (3), it is possible to evaluate the playing effect of each enterprise under main melodies and acceptable melody in industry (Yan, 2016), the criterion of which is that the value of equation (3) is as small as possible. According to the Pareto principle, enterprises which occupy $0.2 \times n$-th or of a higher order in the ranking of playing effects may be termed the advantageous ones, while the others are inferior.

$$
d_{w_{i}}\left(f_{k}, \widetilde{f}\right)=\sqrt{\sum_{j=1}^{m} w_{i j}{ }^{2}\left(\widetilde{f}_{j}-f_{k j}\right)^{2}}, i, k=1,2, \ldots, n
$$

\section{Identification of an Order Parameter}

The order parameter is the macro variable to reflect a systemic motion mode, by which the functional behavior of a system is determined. 
Because the value structure has the same function and role as the order parameter, it can be considered as a concrete expression of the order parameter, i.e., the order parameter plays the guiding and restraining role through the value structure in a system (Xin, Xinan, \& Jianfeng, 2011). In a system, there will only be a unique order parameter that determines its evolution. The above refined main melodies and acceptable melody can be used for the identification of the order parameter. If $y_{R}^{*}$ is a ranking order vector of all enterprises under $w^{*}$ and $y_{k}$ is that of all enterprises under the $k$-th main melody, the deviation between $y_{R}^{*}$ and $y_{k}$ may be expressed as follows:

$$
d_{R k}=\frac{1}{\beta} \sum_{i=1}^{n}\left|y_{R i}^{*}-y_{k i}\right|,
$$

where $\beta$ is a deviation coefficient, which represents the maximum deviation between $y_{R}^{*}$ and $y_{k}$. According to the relationship between deviation and similarity, it is possible to get the similarity $C_{R k}$ between $y_{R}^{*}$ and $y_{k}$ as follows:

$$
C_{R k}=\frac{1}{1+d_{R k}},
$$

The value structure of the main melody with the largest $C_{R k}$ is just the order parameter which leads industry development i.e., it represents the main developing mode of industry.

\section{Classification of Strategic Groups Under the Order Parameter}

In this paper, the number of clustered groups under the order parameter is used to classify the strategic groups in industry because there is only one order parameter in a system.

\section{Analysis of Industrial Environment of Strategic Groups}

\section{Determination of Main Developing Mode of Industry}

Let's assume that an order parameter is $w=(0.1278,0.1963,0.1513,0.0$ $923,0.0742,0.3563)^{\tau}$ ! It is not difficult to find that the order parameter has the most advantage in $w_{6}$ and is relatively balanced in the other five indicators. Therefore, it can be said that the industry pursues 
probably a relatively balanced developing mode in which greater importance is attached to $w_{6}$.

\section{Identification of Main Strategic Group}

There must be an order parameter as well as a strategic group that possesses it in industry, which is called the main strategic group in this paper. From the above illustration, it can be defined as follows: The main strategic group consists of more than 20 percent of enterprises in industry and the value structure of its melody reflects the main developing mode of the industry. It is possible to identify the main strategic group through the identification of the order parameter.

\section{Analysis of Distribution of Strategic Groups in Industry}

It is possible to find the distributive feature of strategic groups in industry based on the classification results. In addition, all strategic groups may be divided into advantageous or inferior ones according to their strength of impact on industry. If most of the enterprises that occupy $0.2 \times n$-th or a higher order in $y_{R}^{*}$ are involved in a strategic group, the group belongs to an advantageous group, otherwise, it is inferior.

\section{Identification of Benchmarks and Synergistic Partners}

From the perspective of Jingyou, the benchmarks should not only reflect the main developing mode of industry but also have higher impact strength than other enterprises in the industry. Therefore, advantageous enterprises involved in a main strategic group of industry, which occupy $0.2 \times n$-th or a higher order in $y_{R}^{*}$, may be identified as benchmarks for other enterprises in industry. In addition, all the enterprises in the same strategic group will become synergistic partners with each other.

\section{Application Paradigm}

The study of paradigm application was used in the performance data of 41 listed companies in an industry in China in 2012-2016. Table 1 shows some financial indicators of listed companies used in this study. 
IJMS 26 (1), 73-97 (2019)

Table 1

The Financial Indicators of Listed Companies used in this Study

\begin{tabular}{clrl}
\hline No & \multicolumn{1}{c}{ Financial indicator } & No & \multicolumn{1}{c}{ Financial indicator } \\
\hline 1 & Earnings per share (RMB), $w_{1}$ & 5 & Net assets per share (RMB), $w_{5}$ \\
2 & Net earnings per share (RMB), $w_{2}$ & 6 & $\begin{array}{l}\text { Rate of return on common } \\
\text { stockholders' equity }(\%), w_{6}\end{array}$ \\
3 & Gross sales (RMB), $w_{3}$ & 7 & Cash flow from operations \\
& & 8 & per share (RMB), $w_{7}$ \\
4 & Net profit (RMB), $w_{4}$ & Gross profit ratio $(\%), w_{8}$ \\
\hline
\end{tabular}

\section{Classification of Strategic Groups}

Tables 2, 3, 4, and 5 show the value structure of acceptable melodies in industry, the main melodies and the order parameters, the ranking orders of playing effects of companies under acceptable melodies, and the results of classification of strategic groups obtained using the method proposed in this study.

\section{Table 2}

The Value Structures of Acceptable Melodies in Industry.

\begin{tabular}{cc}
\hline Year & The acceptable value structure in industry \\
\hline 2012 & $w=(0.1256,0.1282,0.0633,0.0644,0.1145,0.2873,0.1377,0.0850)^{\tau}$ \\
2013 & $w=(0.1191,0.1137,0.0626,0.0721,0.0932,0.3533,0.1020,0.0839)^{\tau}$ \\
2014 & $w=(0.1042,0.1142,0.0385,0.0552,0.0390,0.4055,0.1763,0.0671)^{\tau}$ \\
2015 & $w=(0.0222,0.0719,0.0152,0.0354,0.0116,0.8399,0.0282,0.0297)^{\tau}$ \\
2016 & $w=(0.0351,0.0351,0.0214,0.0290,0.0658,0.6180,0.0542,0.1414)^{\tau}$ \\
\hline
\end{tabular}


IJMS 26 (1), 73-97 (2019)

Table 3

The Main Melodies, Similarities and Order Parameters

\begin{tabular}{|c|c|c|c|}
\hline Year & Main melody & Similarity & $\begin{array}{c}\text { Order } \\
\text { parameter }\end{array}$ \\
\hline \multirow{3}{*}{2012} & $3 w_{2}=(0.1355,0.1318,0.0683,0.0695,0.0972,0.3099,0.0962,0.0917)^{\tau}$ & 0.9304 & \multirow{3}{*}{$5 w_{2}$} \\
\hline & $4 w_{2}=(0.1387,0.1350,0.0700,0.0712,0.0997,0.3171,0.0987,0.0696)^{\tau}$ & 0.9304 & \\
\hline & $5 \mathrm{w}_{2}=(0.1426,0.1387,0.0581,0.0593,0.1025,0.3259,0.1014,0.0715)^{\tau}$ & 0.9358 & \\
\hline \multirow{3}{*}{2013} & $3 w_{1}=(0.1252,0.1195,0.0658,0.0757,0.0980,0.3711,0.0816,0.0631)^{\tau}$ & 0.9069 & \multirow{3}{*}{$4 w_{I}$} \\
\hline & $4 w_{1}=(0.1285,0.1226,0.0544,0.0646,0.1006,0.3809,0.0837,0.0647)^{\tau}$ & 0.9467 & \\
\hline & $5 w_{1}=(0.1254,0.1193,0.0570,0.0675,0.0790,0.3990,0.0849,0.0680)^{\tau}$ & 0.9411 & \\
\hline \multirow{3}{*}{2014} & $3 w_{1}=(0.1095,0.1200,0.0277,0.0452,0.0410,0.4263,0.1853,0.0449)^{\tau}$ & 0.9256 & \multirow{3}{*}{$3 w_{1}$} \\
\hline & $4 w_{1}=(0.1229,0.1332,0.0311,0.0503,0.0463,0.4797,0.0853,0.0512)^{\tau}$ & 0.9214 & \\
\hline & $5 w_{1}=(0.1163,0.1270,0.0321,0.0519,0.0373,0.4947,0.0879,0.0528)^{\tau}$ & 0.9207 & \\
\hline \multirow{2}{*}{2015} & $3 w_{1}=(0.0233,0.0188,0.0159,0.0372,0.0122,0.8830,0.0040,0.0056)^{\tau}$ & 0.9036 & \multirow{2}{*}{$4 w_{i}$} \\
\hline & $4 w_{1}=(0.0156,0.0108,0.0033,0.0257,0.0039,0.9307,0.0042,0.0059)^{\tau}$ & 0.9574 & \\
\hline \multirow{3}{*}{2016} & $3 w_{1}=(0.0369,0.0369,0.0225,0.0305,0.0691,0.6497,0.0314,0.1230)^{\tau}$ & 0.9411 & \multirow{3}{*}{$3 w_{i}$} \\
\hline & $4 w_{1}=(0.0382,0.0383,0.0237,0.0321,0.0517,0.6539,0.0328,0.1293)^{\tau}$ & 0.9367 & \\
\hline & $5 w_{1}=(0.0238,0.0239,0.0079,0.0166,0.0532,0.7085,0.0285,0.1376)^{\tau}$ & 0.9308 & \\
\hline
\end{tabular}

Table 4

The Ranking Orders of Playing Effects of Companies Under the Acceptable Melodies

\begin{tabular}{cccccc|cccccc}
\hline LC & 2012 & 2013 & 2014 & 2015 & 2016 & LC & 2012 & 2013 & 2014 & 2015 & 2016 \\
\hline 1 & 26 & 41 & 31 & 3 & 41 & 22 & 41 & 34 & 40 & 2 & 28 \\
2 & 35 & 33 & 22 & 15 & 8 & 23 & 30 & 35 & 33 & 20 & 26 \\
3 & 31 & 10 & 25 & 17 & 7 & 24 & 27 & 22 & 29 & 31 & 17 \\
4 & 2 & 5 & 3 & 29 & 2 & 25 & 1 & 1 & 1 & 40 & 4 \\
5 & 33 & 39 & 18 & 9 & 22 & 26 & 11 & 21 & 32 & 25 & 39 \\
6 & 23 & 16 & 41 & 1 & 18 & 27 & 18 & 11 & 36 & 39 & 38 \\
7 & 14 & 27 & 37 & 28 & 30 & 28 & 7 & 6 & 2 & 37 & 10 \\
\hline
\end{tabular}

(continued) 
IJMS 26 (1), 73-97 (2019)

\begin{tabular}{cccccc|cccccc}
\hline LC & 2012 & 2013 & 2014 & 2015 & 2016 & LC & 2012 & 2013 & 2014 & 2015 & 2016 \\
\hline 8 & 37 & 28 & 30 & 11 & 14 & 29 & 9 & 2 & 15 & 26 & 33 \\
9 & 38 & 31 & 9 & 8 & 36 & 30 & 6 & 13 & 12 & 34 & 40 \\
10 & 24 & 26 & 39 & 22 & 35 & 31 & 22 & 36 & 35 & 16 & 27 \\
11 & 20 & 29 & 26 & 18 & 32 & 32 & 4 & 4 & 6 & 13 & 16 \\
12 & 34 & 20 & 11 & 6 & 1 & 33 & 3 & 12 & 23 & 32 & 20 \\
13 & 40 & 25 & 14 & 7 & 25 & 34 & 16 & 19 & 27 & 35 & 15 \\
14 & 12 & 9 & 5 & 38 & 3 & 35 & 13 & 8 & 8 & 33 & 5 \\
15 & 32 & 23 & 17 & 12 & 29 & 36 & 8 & 7 & 16 & 23 & 37 \\
16 & 17 & 17 & 20 & 10 & 6 & 37 & 19 & 18 & 13 & 30 & 13 \\
17 & 15 & 40 & 21 & 5 & 24 & 38 & 36 & 24 & 4 & 27 & 19 \\
18 & 21 & 14 & 28 & 19 & 12 & 39 & 5 & 3 & 7 & 36 & 11 \\
19 & 10 & 15 & 19 & 14 & 9 & 40 & 29 & 38 & 24 & 21 & 23 \\
20 & 28 & 30 & 10 & 41 & 21 & 41 & 39 & 32 & 38 & 24 & 34 \\
21 & 25 & 37 & 34 & 4 & 31 & & & & & & \\
\hline
\end{tabular}

Note: $\mathrm{LC}=$ Listed company

Table 5

The Classification of Strategic Groups Under the Order Parameters

\begin{tabular}{ccc}
\hline Year & $\begin{array}{c}\text { Order } \\
\text { parameter }\end{array}$ & Strategic groups \\
& & $5 \mathrm{SG}_{1}(7,1)$ \\
& & $5 \mathrm{SG}_{2}(25,29,37,12,2,30,16,6,33,14,28,24,36,10,26,21,20$, \\
2012 & $5 w_{2}$ & $51,15,39,34,19,5,17,40,11,13,41,8,38,3,35,32,23,22,9)$ \\
& & $5 \mathrm{SG}_{3}(4)$ \\
& & $5 \mathrm{SG}_{4}(18)$ \\
& & $5 \mathrm{SG}_{5}(27)$ \\
& & \\
\end{tabular}

(continued) 
IJMS 26 (1), 73-97 (2019)

\begin{tabular}{|c|c|c|}
\hline Year & $\begin{array}{c}\text { Order } \\
\text { parameter }\end{array}$ & Strategic groups \\
\hline \multirow{5}{*}{2013} & \multirow{5}{*}{$4 w_{1}$} & $4 \mathrm{SG}_{1}(25,18,29,35,1,32,23,17,37,19,3,13,5,33,14,30,28,21$ \\
\hline & & $38,26,24,36,10,39,34,40,22,15,31,20,2,11,9,41,8,7,16,12)$ \\
\hline & & $4 S_{2}(4)$ \\
\hline & & $4 \mathrm{SG}_{3}(6)$ \\
\hline & & $4 \mathrm{SG}_{4}(27)$ \\
\hline \multirow{4}{*}{2014} & \multirow{4}{*}{$3 w_{1}$} & $3 S G_{1}(7,13,38,28,12,9,25,35,6,22,10,27,41,20,2,37,17,39,36$, \\
\hline & & $32,1,5,40,15,31,3,8,19,18,16,30,14,24,26,21,11,33,34,23)$ \\
\hline & & $3 \mathrm{SG}_{2}(4)$ \\
\hline & & $3 \mathrm{SG}_{3}(29)$ \\
\hline \multirow{5}{*}{2015} & \multirow{5}{*}{$4 w_{1}$} & $4 \mathrm{SG}_{1}(22,21,17,1,32,12,37,33,31,15,9,13,5,14,16,8,19,11$ \\
\hline & & $40,23,28,18,3,2,24,7,41,26,38,36,27,20,10,35,39,34,30)$ \\
\hline & & $4 \mathrm{SG}_{2}(25,4)$ \\
\hline & & $4 S G_{3}(6)$ \\
\hline & & $4 \mathrm{SG}_{4}(32)$ \\
\hline \multirow{4}{*}{2016} & \multirow{4}{*}{$3 w_{1}$} & $3 \mathrm{SG}_{1}(25,14,12,4,1,39,30,20,9,28,27,29,17,36,26,24,3,18$ \\
\hline & & $19,37,34,21,41,31,11,10,7,5,13,8,33,2,40,23,6,38,15,35,22)$ \\
\hline & & $3 S G_{2}(16)$ \\
\hline & & $3 \mathrm{SG}_{3}(32)$ \\
\hline
\end{tabular}

Note: $\mathrm{SG}=$ Strategic group

\section{Analysis of Industrial Environment of Strategic Group}

\section{Determination of Main Developing Mode of Industry}

As seen in Table 3, the industry pursued probably a main developing mode which would have attached greater importance to the rate of return on common stockholders' equity $\left(w_{6}\right)$, showing a certain advantage in earnings per share $\left(w_{1}\right)$ and net earnings per share $\left(w_{2}\right)$ in 2012. In 2013, there was almost no change in the developing mode. In 2014, the industry maintained a high advantage in $w_{6^{\prime}}$ and began to focus on building up advantage in cash flow from operations per share $\left(w_{7}\right)$. In 2015, it focused on the exhibition of advantage in $w_{6}$. In 2016, 
it began to build up advantage in gross profit ratio $\left(w_{8}\right)$. There were no other advantages in the most important performance indicators, such as gross sales and net profit in 2012-2016, which showed that the industry had pursued a developing mode to obtain total income by expanding investments rather than increasing business efficiency.

\section{Identification of Main Strategic Group}

From Table 5, it is possible to identify the main strategic groups in industry (Table 6).

Table 6

The Main Strategic Groups (The Number of Listed Companies)

\begin{tabular}{cccccc}
\hline Year & 2012 & 2013 & 2014 & 2015 & 2016 \\
\hline MSG & 5 SG $_{2}(36)$ & $4 S_{1}(38)$ & $3 S_{1}(39)$ & $4 S_{1}(37)$ & $3 S_{1}(39)$ \\
\hline
\end{tabular}

Note: $\mathrm{MSG}=$ Main strategic group

\section{Analysis of Distribution of Strategic Groups}

As seen in Tables 4, 5, and 6, there were 5 groups in 2012, where $5 \mathrm{SG}_{2}$ (MSG) and $5 S_{3}$ were advantageous. In 2013, there were 4 groups, where $4 S_{1}$ (MSG) and $4 S_{2}$ were advantageous. In 2014, 3SG $(M S G)$ and $3 S_{2}$ were advantageous, while $3 S_{3}$ was inferior. In 2015, there were 4 groups, where $4 \mathrm{SG}_{1}$ (MSG) and $4 \mathrm{SG}_{3}$ were advantageous.

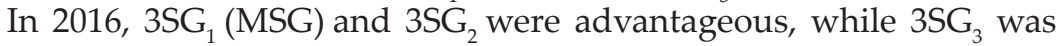
inferior.

\section{Identification of Benchmarks and Synergistic Partners}

Based on Tables 4, 5, and 6, it is possible to identify the benchmarks of all listed companies in industry as follows: LC25, 33, 32, 39, 30, 28, 36 in 2012; LC25, 29, 39, 32, 28, 36, 35 in 2013; LC25, 28, 38, 14, 32, 39, 35 in 2014; LC22, 1, 21, 17, 12, 13, 9 in 2015; LC12, 4, 14, 25, 35, 3, 2 in 2016.

Meanwhile, there will be in existence a synergistic relationship between all companies in the same group; for example, LC1 and 7 which formed $5 S_{1}$ in 2012 could be the closest synergistic partners with each other. 
IJMS 26 (1), 73-97 (2019)

\section{Discussion}

It is possible to discuss the relationship between strategic group and industry performance by using the above analysis of results and the actual performance data of companies in industry. As seen in Table 6, the main strategic groups included more than $80 \%$ of listed companies in industry, and could play very important roles in the development of industry. Table 7 and Figures 3, 4, 5, and 6 describe the performances of industry, main strategic groups, advantageous companies, LC3 and 4 which were the most representative listed companies in industry in terms of gross sales and net profit in 20122016.

Table 7

The Performances of Industry, MSG, Advantageous Companies, LC3 and LC4

\begin{tabular}{|c|c|c|c|c|c|c|}
\hline & $\begin{array}{c}\text { Indicator (100 } \\
\text { million yuan, RMB) }\end{array}$ & 2012 & 2013 & 2014 & 2015 & 2016 \\
\hline \multirow{5}{*}{ Industry } & Gross sales & 12503.3 & 12733.2 & 11766.3 & 9153.7 & 9605.8 \\
\hline & Net profit & -52.93 & 87.73 & 47.82 & -514.9 & 73.25 \\
\hline & Average gross sales & 304.96 & 310.5 & 286.98 & 223.26 & 234.29 \\
\hline & Average net profit & -1.29 & 2.14 & 1.17 & -12.56 & 1.7 \\
\hline & $\begin{array}{c}\text { Indicator (100 } \\
\text { million yuan, RMB) }\end{array}$ & 2012 & 2013 & 2014 & 2015 & 2016 \\
\hline \multirow{4}{*}{$\begin{array}{l}\text { Strategic } \\
\text { group }\end{array}$} & Gross sales & 10168.2 & 10596.9 & 9870.7 & 7369.78 & 9305.4 \\
\hline & Net profit & -152.5 & 27.94 & -14.34 & -498.7 & 65.12 \\
\hline & Average gross sales & 282.45 & 278.87 & 253.1 & 199.18 & 238.6 \\
\hline & Average net profit & -4.24 & 0.74 & -0.37 & -13.5 & 1.67 \\
\hline \multirow{4}{*}{$\begin{array}{l}\text { Advantageous } \\
\text { companies }\end{array}$} & Gross sales & 748.35 & 293.81 & 627.93 & 1547.3 & 2958.5 \\
\hline & Net profit & 24.1 & 27.26 & 20.55 & -240.02 & 134.47 \\
\hline & Average gross sales & 106.91 & 41.97 & 89.70 & 221.04 & 422.14 \\
\hline & Average net profit & 3.44 & 3.89 & 2.94 & -34.29 & 19.21 \\
\hline
\end{tabular}

(continued) 
IJMS 26 (1), 73-97 (2019)

\begin{tabular}{clccccc}
\hline & \multicolumn{2}{c}{ Indicator (100 } & & & & \\
& million yuan, RMB) & 2012 & 2013 & 2014 & 2015 & 2016 \\
& & & & & & \\
\hline \multirow{2}{*}{ LC3 } & Gross sales & 782.14 & 753.29 & 740.46 & 527.59 & 578.82 \\
& Net profit & -40.25 & 7.7 & 9.28 & -45.93 & 16.16 \\
\hline \multirow{2}{*}{ LC4 } & Gross sales & 1915.12 & 1900.26 & 1877.89 & 1641.17 & 1857.1 \\
& Net profit & 100.9 & 58.18 & 57.92 & 9.44 & 89.66 \\
\hline
\end{tabular}

Note: $\mathrm{MSG}=$ Main strategic group

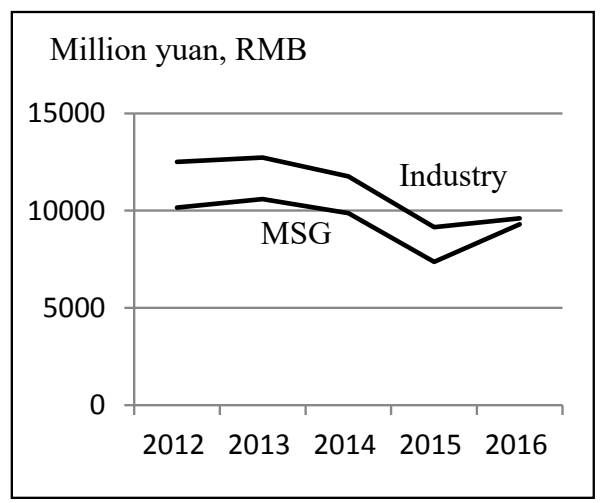

Figure 3. The gross sales of industry and MSG in 2012-2016

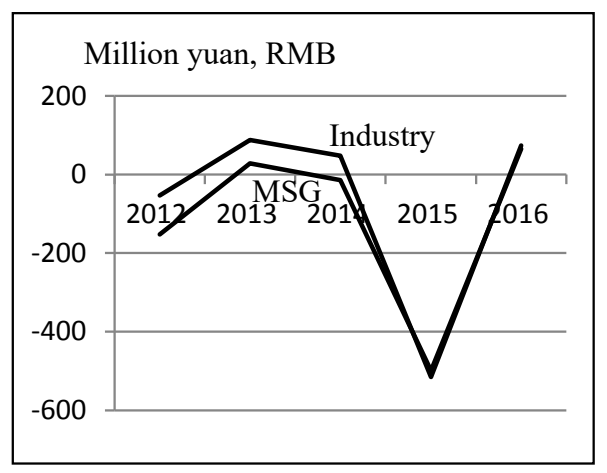

Figure 4. The net profit of industry and MSG in 2012-2016 


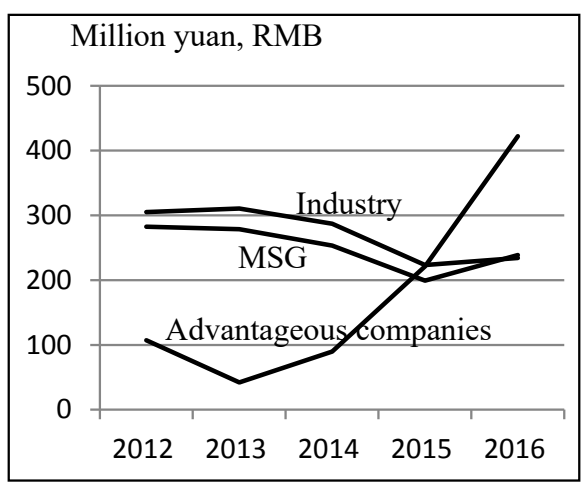

Figure 5. The average gross sales of industry, MSG and advantageous companies in 2012-2016

As seen in Table 7 and Figure 3, the main strategic groups occupied more than 80 percent of the gross sales of listed companies in industry, particularly in 2016, where the main strategic group held the majority of gross sales. However, their performance in net profit was very poor in 2012-2015, for example, the deficit in net profit of the main strategic group had exceeded that of the entire industry in 2015 (Table 7 and Figure 4).

The average performances of the main strategic groups in gross sales and net profit were lower than those of industry in 20122015, because the main strategic groups were composed almost of companies with performances which were relatively low (Figures 5 and 6). Of course, there were large companies such as LC3, 18 and 40 in the main strategic groups, but they did not occupy priorities to impact on industry development (Table 4). LC4 did not lead industry development even though its performance was much higher than other companies, because its value structure was not appropriate to the developing mode of industry (Table 5). In addition, there was almost no difference in the compositions of the main strategic groups in 2012-2014, and their performance in gross sales and net profit showed a relatively slow increase or decrease. However in 2015, there was a serious change in the composition of the main strategic group. Although identified advantageous companies such as LC6, 22, 1, 21, $17,12,13,9$ had occupied a higher order in the playing effect, their 
actual performance in net profit was very poor, which led to a rapid decline of the entire industry in terms of net profit (Figures 4 and 6). The main strategic group including companies such as LC3 and 4 occupied 89 percent of the net profit of industry in 2016.

From a comparative analysis of the performance of the entire industry, the strategic groups and some representative companies, the following describes the findings: 1 ) the size of the strategic group significantly influences the performance of industry, i.e., the larger the strategic group, the greater its impact strength on industry performance whether it be positive or negative to industry development. Of, the more difficult to control is industry performance 2) the composition of strategic group also affects the performance significantly, in other words, the performance of industry is directly related to whether or not the listed companies which are involved in the main strategic group have advantage in important financial indicators such as gross sales and net profit. Although a main strategic group plays the most important role in industry development, it cannot contribute to increase the performance of industry unless the companies included in it have actual abilities in the indicators mentioned; 3) the composition of the main strategic group is also related to the developing mode of industry. For example, the fact that such representative companies such as LC4 and 3 were not included in the main strategic group or had not played any role in industry development in 2012-2015 shows that there were certain problems in the developing mode of industry. The performance of industry in net profit has improved since LC4 was included in the main strategic group, which explains that the industry has formed a new developing mode based on the value structure of LC4 according to the industrial restructuring of the government since 2016.

\section{Conclusion}

A method of studying strategic groups based on the main melody analysis was proposed in this paper, which was different from the previous researches in that it was based on synergy and Jingyou theory rather than the competitive mechanism. The following results were obtained from this study: 1) the synergistic relationship between enterprises in strategic groups and synergistic behavior as a driving 
force for the development of enterprise and strategic groups; 2) individual advantage characteristics as a representation of corporate strategic behavior; 3) the distributive features of strategic groups; 4) the main strategic group and the main developing mode; 5) the benchmark and the synergistic partner; 6 ) the relationship between strategic groups and industry performance.

The following are theoretical contributions of this study: 1) it provided new scientific interpretations of the relationship between enterprises in a strategic group, corporate strategic behavior and the impact of organizational values on the said behavior, and the representation of corporate strategic behavior within the industrial environment according to the objective law of the development of things, which will be helpful in developing strategic group theory and its related scientific fields including organizational behavior, industrial economics and strategic management; 2) it established a reasonable and acceptable analysis method which made it possible to explain the effects of corporate behavior, industrial structure and its strategic features, and the economic situation in an industry in a comprehensive manner as the basis for the idea of sustainable development. The practical contributions of this study are as follows: 1) it is helpful in solving problems faced in modern strategic management practices such as designing strategic plans, innovation in value creation mechanisms, reorganization of relationships between other enterprises in industry and the innovation of management structure, which will enable enterprises to create new growth points for their sustainable development under the current industrial environment; 2) it can be useful in overcoming negative behavior such as excessive competition and monopoly that are deemed conventional and still practised in economic activities, besides promoting a stable and sustainable development of the national economy based on effective collaboration between enterprises in an industry or different industries.

Recommendations for future studies are as follows: 1) there is a need to study the formation mechanism of strategic groups, the interaction between synergy and competition in strategic groups, the relationship between strategic groups and enterprise performance and the relationship between different strategic groups from a more systemic and dynamic standpoint(s); 2) the method and the 
application paradigm proposed in this paper is only limited to an industry. From the standpoint of the national economy, they must be developed into an open system to promote collaboration with enterprises from different industries.

\section{Acknowledgments}

This study is financially supported by the National Science Council of the Republic of China (71271048).

\section{References}

Altuntas, M., Rauch, J., \& Wende, S. (2016). Strategic group performance and dynamics under different economic conditions. The Geneva Papers on Risk and Insurance - Issues and Practice, 41(2), 325-347. DOI: info:doi/10.1057/gpp.2015.28

Bouzid, S., Chaudey, M., Fadairo, M., \& Perdreau, F. (2017). Strategic groups in the French franchising sector. Management and Governance of Networks, 11-33. DOI: 10.1007 /978-3 -319-572765_2

Cho, Y. R., Lee, J. P., \& Kim, K. T. (2016). The competitive strategy in global engineering industry: Strategic group analysis. Proceedings of the 2015 IEEE International Conference on Industrial Engineering and Engineering Management (IEEM), 549-553. DOI: 10.1109/IEEM.2015. 7385707

Claver-Cortes, E., Molina-Azorın, J. F., \& Pereira-Moliner, J. (2006). Strategic groups in the hospitality industry: Intergroup and intragroup performance differences in Alicante, Spain. Tourism Management, 27, 1101-1116. DOI: 10.1016/j. tourman.2005.11.006

Collins, A. J. (2019). Strategic group formation in the El Farol bar problem. Complex Adaptive Systems, 15, 199-211. DOI: 10.1007/978-3-030-20309-2_9

Collins, A. J., \& Frydenlund, E. (2017). Strategic group formation in agent-based simulation. SIMULATION: Transactions of The Society for Modeling and Simulation International, 94(1), 2-26. DOI: $10.1177 / 0037549717732408$

Dess. G. G., \& Davis, P. S. (1984). Generic strategies as determinants of strategic group membership and organizational performance. 
Academy of Management Journal, 27(3), 467-488. DOI: 10. 5465/ 256040

Dornier, R., Selmi, N., \& Delecolle, T. (2012). Strategic groups structure, positioning of the firm and performance: A review of literature. International Business Research, 5(2), 27-40. DOI: 10.5539/ibr.v5n2p27

Godlewska-Majkowska, H., \& Komor, A. (2017). Regional strategic groups as a tool of enterprises localization analysis on automotive industry in the European union. Inzinerine Ekonomika-Engineering Economics, 28(1), 35-46. DOI: 10.5755/ j01.ee.28.1.7799

Haken. H. (1977). Synergistics. Berlin, Heidelberg, NewYork: SpringerVerlag.

Hoyta, J., \& Sherman, H. (2004). Strategic groups, exit barriers and strategy decision constraints in high-tech companies. Journal of High Technology Management Research, 15, 237-247. DOI: 10.1016/j.hitech.2004.03.005

Huang, K. F. (2009). How do strategic groups handle cognitive complexity to sustain competitive advantage? A commentary essay. Journal of Business Research, 62, 1296-1298. DOI: 10.1016 /j.jbusres.2008.12.007

Hunt, M. (1972). Competition in the major home appliance industry (Unpublished Doctoral Dissertation). Harvard University.

Jardon, C., Molodchik, M., \& Paklina, S. (2018). Strategic behaviour of Russian companies with regard to intangibles. Management Decision, 56(11), 2373-2390. DOI: 10.1108/MD-04 -2017 -0399

Jean-Pierre, J., \& Schreuder, H. (2015). From coal to biotech: The transformation of DSM with business school support. SpringerVerlag, Berlin:Heidelberg.

Johnsona, A. J., Johnsonb, H. C., Devadossc, S., \& Foltz, J. (2011). Strategic group analysis of U.S. food businesses using the two-step clustering method. International Food and Agribusiness Management Review, 14(2), 83-102. DOI: 10.1093/heapol/ czq023

List, J. A., Neilson, W. S., \& Price, M. K. (2016). The effects of group composition in a strategic environment: Evidence from a field experiments. European Economic Review, 90, 67-85. DOI: 10.1016/j.euroecorev.2016.02.019

Martinez-Torres, M. R., Toral-Marín, S. L. (2010). Strategic group identification using evolutionary computation. Expert Systems with Applications, 37(7), 4948-4954. DOI: 10.1016/j. eswa.2009.12. 019 
Mas-Ruiz, F. J., Ruiz-Conde, E., \& Calderon-Martinz, A. (2018). Strategic group influence on entry mode choices in foreign markets. International Business Review, 27(6), 1259-1269. DOI: 10.1016/j.ibusrev.2018.05.007

Mas-Ruiz, F., \& Ruiz-Moreno, F. (2017). How strategic groups act competitively within and across markets. Managerial and Decision Economics, 38(7), 1017-1032. DOI: 10.1002 /mde. 2842

McGee, J., \& Thomas, H. (1986). Strategic groups: Theory, research and taxonomy. Strategic Management Journal, 7(2), 141-160. DOI: $10.1002 /$ smj.4250070204

Moore. F. (1996). The death of competition: Leadership and strategy in the age of business ecosystems. New York: Harper Business.

Murthia, B. P. S., Rasheedb, A. A., \& Gollc, I. (2013). Empirical analysis of strategic groups in the airline industry using latent class regressions. Managerial and Decision Economics, 34, 59-73. DOI: $10.1002 /$ mde. 2574

Pietrzak, M., Paliszkiewicz, J., Jalosinski, K., \& Brzozowski, A. (2015). Case study of strategic group map application used as a tool for knowledge management. Journal of Computer Information Systems, 55(2), 68-77. DOI: 10.1080/08874417.2015.11645758

Porter, M. (1979). The structure within industries and enterprises' performance. Review of Economics and Statistics, 68(2), 79-91. DOI: $10.2307 / 1924589$

Porter, M. (1980). Competitive strategy: Techniques for analyzing industries and competitors, Free Press, New York.

Pozo, H., da Silva, O. R., \& Tachizawa, T. (2017). The influence of performance objectives on the implementation of lean manufacturing practices: An analysis based on strategic groups. Cogent Business \& Management, 4(1), 1-18. DOI: 10.1080/23311975.2017. 1405718

Prior, D., \& Surroca, J. (2006). Strategic groups based on marginal rates: An application to the Spanish banking industry. European Journal of Operational Research, 170, 293-314. Retrieved from http://doc88.com/p-7408223882493.html

Sabourin, V. (1999). Technological revolutions and the formation of strategic groups. Journal of Engineering and Technology Management, 16(3), 271-293. DOI: 10.1016/s09234748(99)00012-0

Si, Y. (2016). Main melody analysis method and solution based on the ideal point utility model (Chinese). Journal of Northeastern University (Natural Science), 37(9), 1359-1363. 
Sonenshein, S., Nault, K., \& Obodaru, O. (2017). Competition of a different flavor: How a strategic group identity shapes competition and cooperation. Administrative Science Quarterly, 62(4), 626-656. DOI: 10.1177/0001839217704849

Wen, X., Zhao, X., \& Gu, J. (2011). Identification method for system order parameter based on GPEM main melody analysis and its application (Chinese). Operation and Management, 21(3), 168-175. Retrieved from https://www.docin.com/p-988149448. html

Yiannakopoulos, Y., Magoutas, A., \& Chountalas, P. (2017). Strategic competition analysis and group mapping: The case of the Greek insurance industry. Journal of Economics and Business, XX(1), 41-65. Retrieved from http://xueshu.baidu.com/usercenter/ paper

Zhao, X., Liu, B., \& Xu, H. (2006). A Study on the impact of the thought of conforming to the natural rule on the progress of human society. Science Technology and Dialectics, 23(2), 32-34. Retrieved from http://en.cnki.com.cn/Article_en/CJFDTOTALKXBZ 200602008.htm

Zhao, X., Zhu, C., \& Wang, Y. (2012). Jingyou evaluation theory, method and application (Chinese). Chinese Science Publishing House.

Zucchini, L., Bohmer-Horlander, S., \& Kretschmer, T. (2018). Competitive pressure: competitive reactions at the grouplevel. Industry and Innovation, 26(2), 1-24. DOI: 10.1080/ 13662716.2018.1526666

Zuniga-Vicentea, J. A., de la Fuente-Sabateb, J. M., \& SuarezGonzaleza, I. (2004). Dynamics of strategic group membershipperformance linkage in rapidly changing environments. Journal of Business Research, 57, 1378-1390. DOI: 10.1016/S01482963(03) 00071-7 